\title{
Análise da percepção de estudantes do Ensino Médio acerca do processo de aprendizagem em Química
}

\author{
Analysis of the perception of High School students about the Chemistry learning process \\ Análisis de la percepción de los estudiantes de Secundaria sobre el proceso de aprendizaje en
}

Química

Recebido: 08/02/2021 | Revisado: 12/02/2021 | Aceito: 18/02/2021 | Publicado: 27/02/2021

Nathalia da Silva Tavares

ORCID: https://orcid.org/0000-0001-9127-5576

Universidade Federal da Paraíba, Brasil

E-mail: nathaliatavares101@ hotmail.com

Kalline de Almeida Alves Carneiro

ORCID: https://orcid.org/0000-0002-7477-2586

Universidade Federal da Paraíba, Brasil

E-mail: kallinequimica2014@gmail.com

Maria Betania Hermenegildo dos Santos

ORCID: https://orcid.org/0000-0001-8311-9709

Universidade Federal da Paraíba, Brasil

E-mail: mbetaniahs@gmail.com

Ramon Freire da Silva

ORCID: https://orcid.org/0000-0002-4465-2006 Universidade Federal da Paraíba, Brasil

E-mail: ramonsilvagro@gmail.com

Rodolpho José de Almeida Nascimento

ORCID: https://orcid.org/0000-0001-7946-0875

Universidade Federal da Paraíba, Brasil E-mail: rjan85@gmail.com

Antônio Inácio Diniz Júnior

ORCID: https://orcid.org/0000-0002-2207-9376

Universidade Federal Rural de Pernambuco, Brasil E-mail: antonioinaciodj@gmail.com

Thiago Pereira da Silva

ORCID: https://orcid.org/0000-0002-3399-6276

Universidade Federal Vale do São Francisco, Brasil

E-mail: profthiagopereira.silva@gmail.com

\begin{abstract}
Resumo
Esta pesquisa teve como objetivo analisar as percepções de estudantes do terceiro ano do ensino médio em cidades do brejo paraibano acerca do processo de aprendizagem na disciplina de Química. Para tanto, compreende-se que o aprendizado de Química é fundamental para o entendimento de vários fenômenos e transformações que ocorrem no nosso cotidiano, possibilitando a relação teoria e prática de vários conceitos químicos. Assim, para que esse tipo de aprendizagem ocorra, é necessário que o ensino possibilite ao educando ir além da memorização de conteúdo, pois o processo de ensino e aprendizagem deve acontecer dentro de uma perspectiva construtiva. Para construção dos dados, realizamos um estudo de natureza quantitativa, interpretativa e descritiva, com quantificação de dados. O levantamento de dados ocorreu por meio da aplicação de um questionário composto por perguntas objetivas. A pesquisa foi realizada em quatro municípios situados no brejo paraibano, sendo desenvolvidas em escolas estaduais dos municípios de Arara, Areia, Bananeiras e Solânea. Os resultados alcançados apontam a necessidade de mudanças metodológicas e didáticas que possam aprimorar cada vez mais a aprendizagem de conceitos químicos. Ademais, destacamos a necessidade do uso de diferentes abordagens de ensino, tais como o uso da contextualização e da experimentação como estratégias fundamentais para o melhor aprendizado dos discentes. Compreende-se que o ensino apoiado, a partir dessas perspectivas possibilita uma maior motivação dos estudantes em aprender Química, pois além de explorar conteúdos relacionados ao seu cotidiano, tornar-se-ão cidadãos capazes de desenvolver o senso crítico e reflexivo.
\end{abstract}

Palavras-chave: Ensino; Química; Percepção; Alunos.

\footnotetext{
Abstract

This research aimed to analyze the perceptions of students of the third year of high school in cities of the swamp of Paraíba about the learning process in the discipline of chemistry. Therefore, it is understood that learning chemistry is
} 
fundamental for the understanding of various phenomena and transformations that occur in our daily lives, enabling the relationship between theory and practice of various chemical concepts. Thus, for this type of learning to occur, it is necessary that teaching enables the student to go beyond the memorization of content, as the teaching and learning process must take place within a constructive perspective. For data construction, we carried out a quantitative, interpretive and descriptive study, with data quantification. Data collection took place through the application of a questionnaire composed of objective questions. The research was carried out in four municipalities located in the swamp of Paraíba, being developed in state schools in the municipalities of Arara, Areia, Bananeiras and Solânea. The results achieved point to the need for methodological and didactic changes that can increasingly improve the learning of chemical concepts. In addition, we highlight the need to use different teaching approaches, such as the use of contextualization and experimentation as fundamental strategies for the best learning of students. It is understood that the supported teaching, from these perspectives allows a greater motivation of students to learn Chemistry, because in addition to exploring content related to their daily lives, they will become citizens capable of developing a critical and reflective sense.

Keywords: Chemistry; Teaching; Perception; Students.

\section{Resumen}

Esta investigación tuvo como objetivo analizar las percepciones de estudiantes de tercer año de bachillerato en ciudades del pantano de Paraíba sobre el proceso de aprendizaje en la disciplina de la Química. Por tanto, se entiende que el aprendizaje de la Química es fundamental para la comprensión de diversos fenómenos y transformaciones que ocurren en nuestra vida diaria, posibilitando la relación entre la teoría y la práctica de diversos conceptos químicos. Así, para que se produzca este tipo de aprendizajes, es necesario que la enseñanza permita al alumno ir más allá de la memorización de contenidos, ya que el proceso de enseñanza y aprendizaje debe darse desde una perspectiva constructiva. Para la construcción de los datos se realizó un estudio cuantitativo, interpretativo y descriptivo, con cuantificación de datos. La recolección de datos se realizó mediante la aplicación de un cuestionario compuesto por preguntas objetivas. La investigación se llevó a cabo en cuatro municipios ubicados en el pantano de Paraíba, desarrollándose en escuelas estatales de los municipios de Arara, Areia, Bananeiras y Solânea. Los resultados obtenidos apuntan a la necesidad de cambios metodológicos y didácticos que puedan mejorar cada vez más el aprendizaje de conceptos químicos. Además, destacamos la necesidad de utilizar diferentes enfoques de enseñanza, como el uso de la contextualización y la experimentación como estrategias fundamentales para el mejor aprendizaje de los estudiantes. Se entiende que la docencia apoyada, desde estas perspectivas, permite una mayor motivación de los estudiantes para aprender Química, pues además de explorar contenidos relacionados con su vida cotidiana, se convertirán en ciudadanos capaces de desarrollar un sentido crítico y reflexivo.

Palabras clave: Enseñanza; Química; Percepción; Estudiantes.

\section{Introdução}

A Química é uma ciência presente no nosso cotidiano, por isso é de suma importância obter o entendimento desta área de conhecimento, como fonte de aprendizado que possa problematizar o conhecimento científico e seus diferentes desdobramentos em sociedade. Por sua vez, o processo de ensinar e aprender conteúdos químicos deve abranger conhecimentos interdisciplinares que estejam relacionados ao desenvolvimento social, ambiental, econômico e político da sociedade. Nesse sentido, Mendonça (2014) expressa que se torna cada vez mais imprescindível que os aspectos relacionados à teoria e prática da Química esteja entrelaçado com o cotidiano dos estudantes e alinhados a problemas reais para que esses encontrem sentidos e estabeleçam relações com as informações integradas com a sociedade, para que o processo de aprender saberes químicos se transforme em algo significativo.

Silva, Siqueira e Goi (2019), afirma que as dificuldades no aprendizado em ciências da natureza, em específico, na Química, ocorrem muitas vezes pela falta de aulas práticas e da contextualização, o que ocasiona uma desmotivação dos estudantes nas aulas teóricas. Por isso, o autor discorre que o professor deve ser o facilitador da aprendizagem por meio de um ensino voltado ao cotidiano, com aulas problematizadoras que permita a contextualização, questionamentos e investigação, relacionando o fazer e o pensar, viabilizando a melhoria no rendimento do discente.

Nesse pensamento, Mól (2017) relata que o ensino de Química deve ser dinâmico e contextualizado, com a finalidade de possibilitar ao educando uma aprendizagem além da memorização de conteúdos e fórmulas matemáticas, pois o processo de ensino e aprendizagem deve ocorrer por meio de uma perspectiva construtivista. Essa perspectiva apoia a visão de que o processo de ensino e aprendizagem são entidades indissociáveis na construção de conhecimento, entretanto interdependentes, 
como se fossem as faces de uma mesma moeda. Nesse sentido, o ato de ensinar está entrelaçado pelo objetivo de possibilitar a aprendizagem, sendo uma forma de significar o que o docente faz em sala de aula, assim, a relação entre o que o educador executa e a efetividade do educando em aprender, é o que nominamos por ensinar (Kubo \& Botomé, 2001). Dessa forma, ensinar é o alinhamento entre o que um docente faz e a aprendizagem de um estudante.

Sobre a aprendizagem, Kubo e Botomé (2001) expressam que trata-se de um processo que pode ocorrer individualmente, mas quando é mediado por um indivíduo, o ato de aprender ocasiona um nível de generalização, na qual aquilo que é ensinado, quando compreendido, ganha significado para o estudante, e a partir disso, o estudante pode conseguir realizar interpretações da sua própria realidade. Os autores ainda discorrem que ambos caminham juntos, e possibilitam que as pessoas construam conhecimentos e compreendam os múltiplos desdobramentos da Ciência e suas mais variadas aplicações.

Nesse sentido, torna-se necessário analisar as percepções dos estudantes a respeito do processo de aprendizagem quando estuda Química. Segundo Giacomini e Muechen (2015) é cada vez mais indispensável alterar a visão acrítica e dogmática do processo de ensino e aprendizagem, em que o estudante apenas enxerga o professor como um transmissor do saber, onde eles atuam como receptores do conhecimento. $\mathrm{O}$ autor ainda ratifica que uma primeira modificação que possa ser alcançada é por meio do diálogo entre o estudante e o professor, visto que esse último é um mediador e articulador do saber científico e escolar, transformando o aluno como sujeito ativo do conhecimento.

Por isso, o uso de novas metodologias participativas que tornem os estudantes do ensino médio mais ativos em sala de aula, é cada vez mais necessário, uma vez que reconhecemos que os conteúdos de Química contribuem de maneira positiva para o seu enriquecimento intelectual colaborando com a formação para o exercício consciente da sua cidadania. Diante disso, é fundamental avaliar à percepção dos alunos em relação aos métodos didáticos desenvolvidos pelo professor em sala de aula, observando o desempenho deles na abordagem de cada conteúdo e quais os impactos na sua aprendizagem, pois o estudante ativo nas aulas gera uma motivação que facilita o processo de aprendizagem.

A motivação torna-se um fator importante neste processo, uma vez que, incentivar os alunos mostrando a importância que a disciplina possui para o entendimento de vários fenômenos presentes em seu contexto sociocultural, faz com que eles tenham um maior interesse em aprender os conteúdos da Química.

Para despertar o interesse do estudante, é necessário que o docente lecione esta ciência utilizando processos de contextualização, problematizando os conteúdos com o cotidiano dos discentes. Como afirma Lima \& Leite (2012) para que o ensino possibilite uma inter-relação entre os conceitos e o cotidiano dos estudantes, pressupõe-se a necessidade de um ensino diferenciado, baseado na construção de significados, incorporando valores que explicitem a realidade, com uma abordagem social e cultural. Logo, facilitar os meios pelos quais o discente aprende de maneira mais dinâmica, indiretamente conseguiremos alcançar um aprendizado mais efetivo.

Diante deste contexto, este trabalho tem como objetivo analisar as percepções de estudantes do terceiro ano do ensino médio de quatro cidades do brejo paraibano, acerca do processo de aprendizagem na disciplina de Química. Assim, almeja-se tecer observações em relação aos diferentes posicionamentos dos estudantes a respeito da importância da desta ciência no cotidiano, além de suas visões concernentes ao aprendizado nesta disciplina. Vale destacar que também buscaremos verificar como os educandos sugerem que a Química se torne uma disciplina motivadora, contrapondo-se a uma disciplina de conteúdos de memorização.

\section{Metodologia}

O presente estudo é caracterizado dentro de uma perspectiva quantitativa, interpretativa e descritiva. Para Richardson (1999); Diehl (2004), pesquisa quantitativa caracteriza-se pela quantificação, tanto na coleta quanto no tratamento das informações, utilizando-se de técnicas estatísticas; esse tipo de pesquisa tem a finalidade de evitar possíveis distorções de 
análise e interpretação dos resultados e frequentemente é aplicado nos estudos descritivos, por procura descobrir e classificar a relação entre variáveis, os quais propõem descobrir as características de um fenômeno

De acordo com Pereira, Shitsuka, Parreira e Shitsuka, a coleta de dados quantitativos ou numéricos é realizada por:

Meio do uso de medições de grandezas e obtém-se por meio da metrologia, números com suas respectivas unidades. Estes métodos geram conjuntos ou massas de dados que podem ser analisados por meio de técnicas matemáticas como é o caso das porcentagens, estatísticas e probabilidades, métodos numéricos, métodos analíticos e geração de equações e/ou fórmulas matemáticas aplicáveis a algum processo.

Fachin (2003), afirma que o questionário é um dos instrumentos utilizados para coletar os dados na pesquisa quantitativa, uma vez que esse apresenta variáveis distintas, cujas análises são geralmente apresentadas através de tabelas e gráficos.

Os participantes dessa pesquisa foram 102 estudantes das turmas do terceiro ano do Ensino Médio, das escolas da rede estadual da Paraíba, localizadas nos municípios de Arara, Areia, Bananeiras e Solânea, cidades de médio porte, desenvolvidas e que possuem diversas escolas de diferentes esferas. A escolha dessas turmas ocorreu em virtude da busca de alcançar o nosso objetivo que era avaliar a percepção dos estudantes sobre a Química desde o $1^{\circ}$ ano até o atual momento do $3^{\circ}$ ano do ensino médio.

A escolha dessas cidades para a abordagem e desenvolvimento desta pesquisa, ocorreu em virtude de suas localizações serem próximas e circunvizinhas a Universidade Federal da Paraíba, a qual contribui diretamente na evolução do ensino da educação básica, por meio de ações como, organização de oficinas, projetos de extensões e eventos que facilitam a qualificação dos professores.

Os estudantes participantes tinham uma faixa etária média entre 16 e 21 anos, variados entre o sexo masculino e feminino e eram moradores tanto da zona urbana, quanto zona rural.

A produção dos dados foi realizada por meio de questionário, o qual foi aplicado durante o período de dois meses. Vale destacar que, de acordo com Severino (2007) o questionário é uma ferramenta de coleta de dados bastante viável, pois possibilita a construção de um conjunto de perguntas que devem ser respondidas por escrito pelo informante, sem a presença do pesquisador e que ao final, fornecem uma gama de informações que podem ser exploradas e sistematizadas em uma pesquisa científica.

O questionário continha seis questões, conforme será apresentado no Quadro 1. As questões estavam relacionadas à presença da Química no cotidiano, sua importância, dificuldades de aprendizagem e seus motivos, gosto pela disciplina e motivação para estudá-la. 
Quadro 1. Questionário aplicado com os discentes.

\begin{tabular}{|l|l|}
\hline \multicolumn{1}{|c|}{ Perguntas } & \multicolumn{1}{c|}{ Respostas } \\
\hline $\begin{array}{l}1^{\circ} \text { ) Para você, onde há Química no seu } \\
\text { cotidiano? }\end{array}$ & $\begin{array}{l}\text { A) Faz parte de tudo no nosso cotidiano; B) Presente nos remédios; C) Presente nos solos; D) } \\
\text { Não existe a presença de Química em nada no meu cotidiano. }\end{array}$ \\
\hline $\begin{array}{l}2^{\circ} \text { ) Qual a importância da disciplina de } \\
\text { Química? }\end{array}$ & A) Muito importante; B) Importante; C) Razoável; D) Não vejo importância. \\
\hline $\begin{array}{l}\left.3^{\circ}\right) \text { Você tem dificuldade de aprendizagem } \\
\text { no ensino de Química? }\end{array}$ & A) Sim; B) Não; C) Não Sei. \\
\hline $\begin{array}{l}\left.4^{\circ}\right) \text { Quais os motivos das suas dificuldades } \\
\text { em aprender Química? }\end{array}$ & $\begin{array}{l}\text { A) Vejo importância, mas não me dedico; B) A metodologia utilizada pelo professor não } \\
\text { envolve o cotidiano; C) Não consigo perceber aplicação prática da Química, por isso } \\
\text { dificulta meu aprendizado; D) É difícil de aprender por causa das regras de nomenclatura; E) } \\
\text { Não vejo importância por isso sinto dificuldade; F) A metodologia utilizada pelo professor } \\
\text { envolve o cotidiano, mas não me atrai; G) É difícil de aprender por causa dos cálculos; H) É } \\
\text { difícil de aprender por causa da competição entre eu e meus colegas. }\end{array}$ \\
\hline $\begin{array}{l}\left.5^{\circ}\right) \text { Você gosta de Química? } \\
6^{\circ} \text { Química? Você se sente motivado a estudar }\end{array}$ & \begin{tabular}{l} 
A) Muito; B) Normal; C) Mais ou menos; D) Pouco; E) Não gosto. \\
\hline
\end{tabular} \\
\hline
\end{tabular}

Fonte: Autores.

Para realizarmos a análise dos dados, nos empenhamos em apresentar o máximo de dados que foram coletados com os diferentes sujeitos da pesquisa, buscando apresentá-los por meio de gráficos para que possibilitasse uma melhor interpretação e descrição dos dados.

Vale salientar que neste estudo apresentamos gráficos para melhor caracterizar os dados alcançados, como forma de apontar elementos concernentes as percepções que mais emergiram durante a coletânea da visão dos estudantes do ensino médio. Assim, o uso de gráficos é uma forma de auxiliar o processo interpretativo e descritivo dos dados, em que também autoriza qualificar de forma impessoal a análise de dados.

\section{Resultados e Discussão}

Nesta seção, apresentamos os resultados alcançados por meio da aplicação de um questionário. A seguir, ilustramos a análise dos dados apontando a quantificação em percentual, seguidas da caracterização e descrição das questões analisadas. Inicialmente, exibimos na Figura 1, as respostas dos estudantes a primeira pergunta, referente à percepção deles em relação à Química no cotidiano. 
Figura 1. Para você, onde há Química no seu cotidiano? A) Faz parte de tudo no nosso cotidiano; B) Presente nos remédios; C) Presente nos solos; D) Não existe a presença de Química em nada no meu cotidiano.

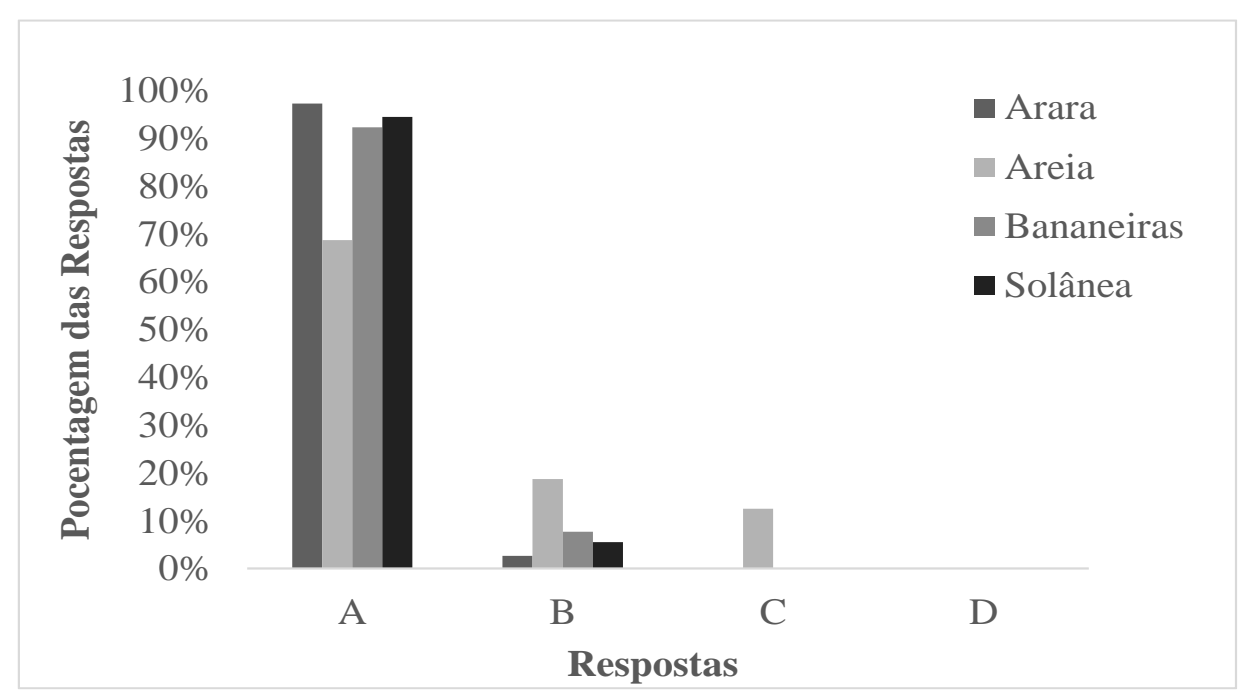

Fonte: Autores.

Ao analisar a Figura 1, observa-se que os alunos do município de Arara (97,3\%) e Solânea (92,3\%) foram os que mais perceberam a presença da Química, afirmando que esta ciência está presente em tudo no nosso cotidiano. A partir destes dados, compreende-se que quando os conteúdos de Química são trabalhados buscando manter uma relação com o cotidiano dos alunos, pode colaborar para despertar interesse e motivação por esta ciência, gerando uma aprendizagem construtiva. Além disso, quando estes conteúdos são vinculados a contextos históricos, políticos, econômicos e culturais, dentro de uma perspectiva construtivista, percebe-se que o aluno se torna ativo no processo de aprendizagem (Ouriques, Ferreira, Welter, Braibante, \& Reis, 2018).

Essa importância da Química reconhecida pelo estudante é um fator positivo para o processo de aprendizagem, que se dá de forma mais efetiva, quando as práticas de ensino são trabalhadas dentro de uma perspectiva contextualizada, utilizando diferentes metodologias participativas que colaboram efetivamente para garantir uma aprendizagem construtiva.

A Figura 2, apresenta a média e o desvio padrão referente a questão 1. 
Figura 2. Média e desvio padrão referente ao primeiro questionamento: Para você, onde há Química no seu cotidiano? A) Faz parte de tudo no nosso cotidiano; B) Presente nos remédios; C) Presente nos solos; D) Não existe a presença de Química em nada no meu cotidiano.

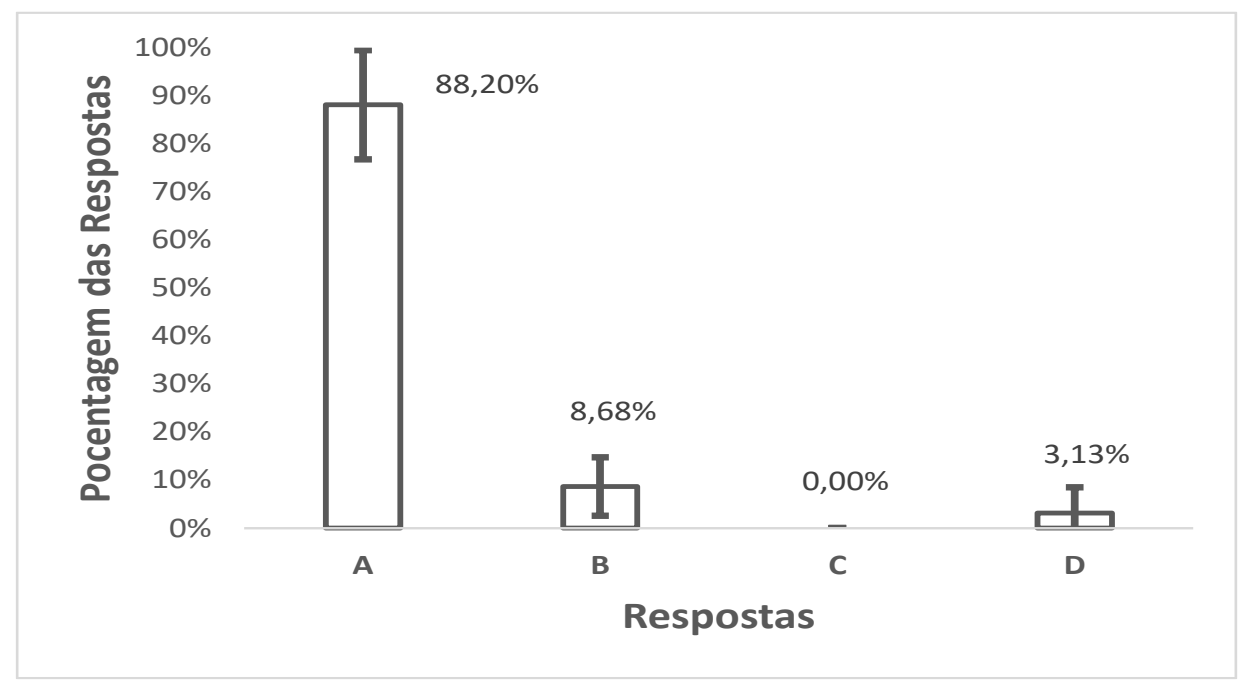

Fonte: Autores.

Considerando as análises das médias e desvio padrão na Figura 2, observa-se que o valor de 88,20\% é consideravelmente maior do que os resultados das outras opções, justificando assim, a importância da Química apresentado pelos alunos do município de Arara. Mediante esse questionamento, observa-se que a falta de uma prática pedagógica que seja trabalhada dentro de uma perspectiva construtivista, contribui diretamente para o desenvolvimento de um ensino baseado no modelo transmissão-recepção dessa ciência, gerando uma imensa aversão dos educandos em querer aprender os conteúdos. Na maioria das vezes, os estudantes não conseguem compreender o conteúdo explorado em sala de aula, por não descobrir sua importância para o dia a dia, e assim, não são capazes de associá-lo, o que causa um desinteresse pelos conteúdos abordados (Leite \& Lima, 2015).

Em seguida, buscou-se analisar entre os estudantes, qual a importância que eles atribuem a disciplina de Química. Os resultados podem ser observados na Figura 3.

Figura 3. Qual a importância da disciplina? A) Muito importante; B) Importante; C) Razoável; D) Não vejo importância.

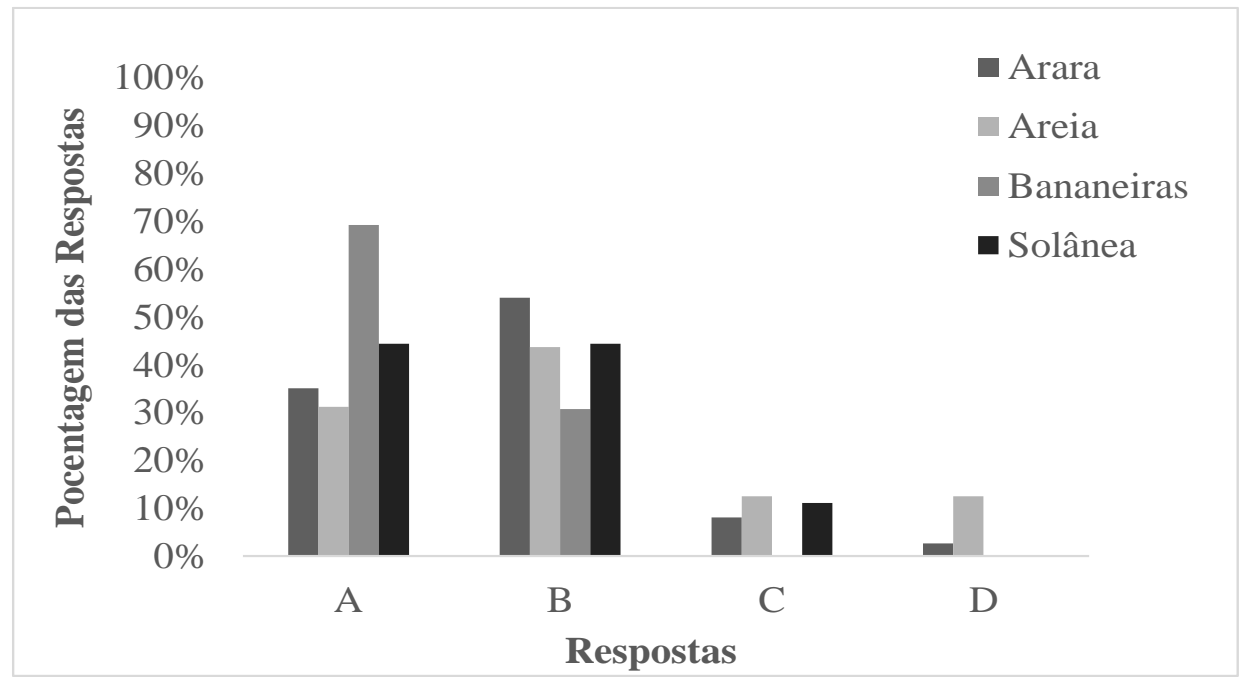

Fonte: Autores. 
Ao analisar a Figura 3, percebe-se que a maioria dos participantes da pesquisa das 4 cidades, analisaram a disciplina de Química entre os itens, muito importante e importante, o que pode ser um ponto positivo, já que os conteúdos podem ter sido trabalhados trazendo aspectos do contexto sociocultural do estudante, gerando um bom desempenho na aprendizagem destes sujeitos. Os alunos de Bananeiras destacam-se com um percentual de $70 \%$ ao classificar como muito importante e a cidade de Arara, com percentual acima de 50\%, classificando como importante.

Apenas uma minoria dos estudantes das 4 cidades, classificou a importância da disciplina através dos itens, razoável e não vejo importância, o que pode ter relação direta com a falta de afinidade com a disciplina ou pelo fato de não conseguir perceber a importância da Química, por considerarem essa ciência complexa, já que em muitos casos ela é trabalhada dentro do modelo transmissão-recepção, a partir do uso excessivo da memorização de conceitos, fórmulas matemáticas, algoritmos e entre outros, onde o discente atua como agente passivo do processo de ensino e de aprendizagem.

Para Vargas Júnior, (2015) a presença do estudante ativo em sala de aula favorece o seu crescimento no processo de ensino, o que colabora para que ele atribua importância a sua aprendizagem no ensino de Química. Nesse contexto, o aluno passa de observador, passivo e receptor de conhecimento, para um sujeito ativo, reflexivo e crítico, construindo a sua própria aprendizagem de maneira motivadora.

Freire, Silva Júnior e Silva (2011) relata em seu estudo, que a Química é vista pelos educandos do ensino médio como uma disciplina abstrata e complexa. Essa mesma visão permanece entre estudantes do nível superior ao ingressarem em seus respectivos cursos.

A Figura 4, apresenta a média e o desvio padrão referente à questão 2.

Figura 4. Média e desvio padrão sobre a pergunta: Qual a importância da disciplina? A) Muito importante; B) Importante; C) Razoável; D) Não vejo importância.

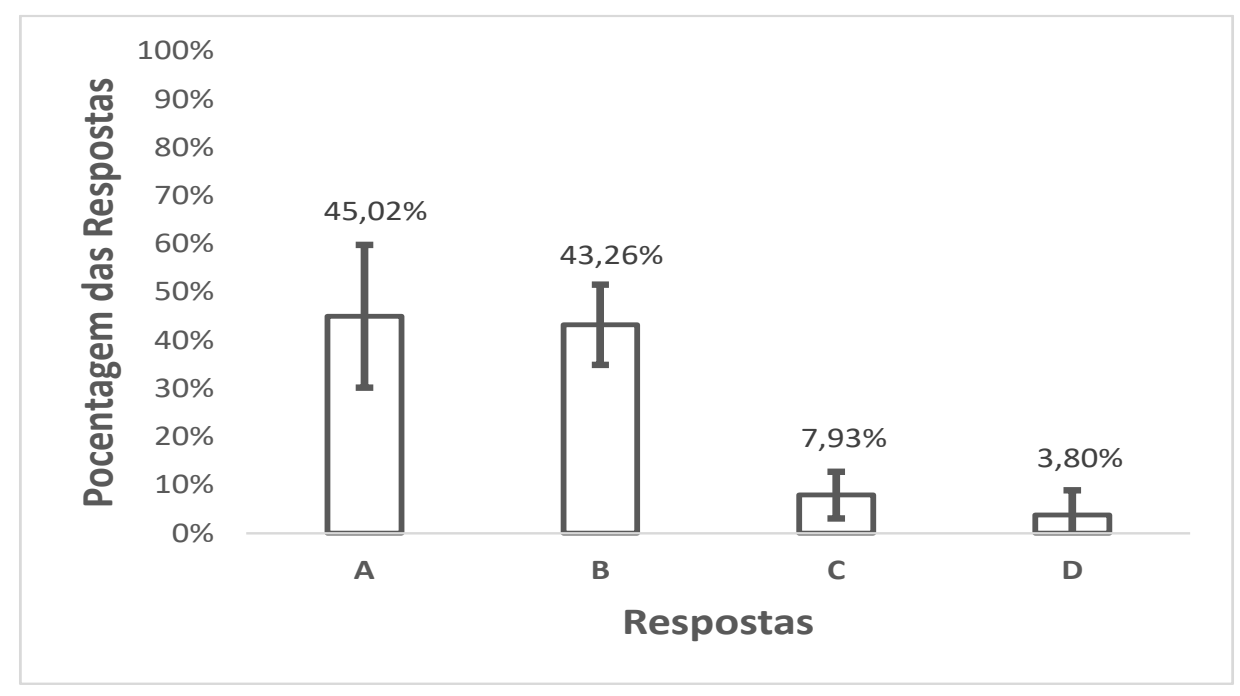

Fonte: Autores.

Na Figura 4, observa-se que 45,02\% dos discentes consideraram a Química como uma disciplina muito importante e 43,26\% importante. Esses resultados têm relação com as boas práticas pedagógicas adotadas pelos docentes em sala de aula, que possivelmente vem colaborando para que os estudantes reconheçam esta ciência como importante. Para Bastos, Nardi, Diniz \& Caldeira (2004) relatam que o educador deve apresentar habilidades e competências para inovar e utilizar novas metodologias de ensino, motivando os estudantes por meio da arte de ensinar, no intuito de conduzi-los para que tenham uma aprendizagem sólida. 
Em seguida, buscou-se levantar entre os estudantes, se eles apresentam dificuldades de aprendizagem no ensino de Química. Esses dados estão representados na Figura 5.

Figura 5. Você tem dificuldade na aprendizagem do ensino de Química? A) Sim; B) Não; C) Não sei.

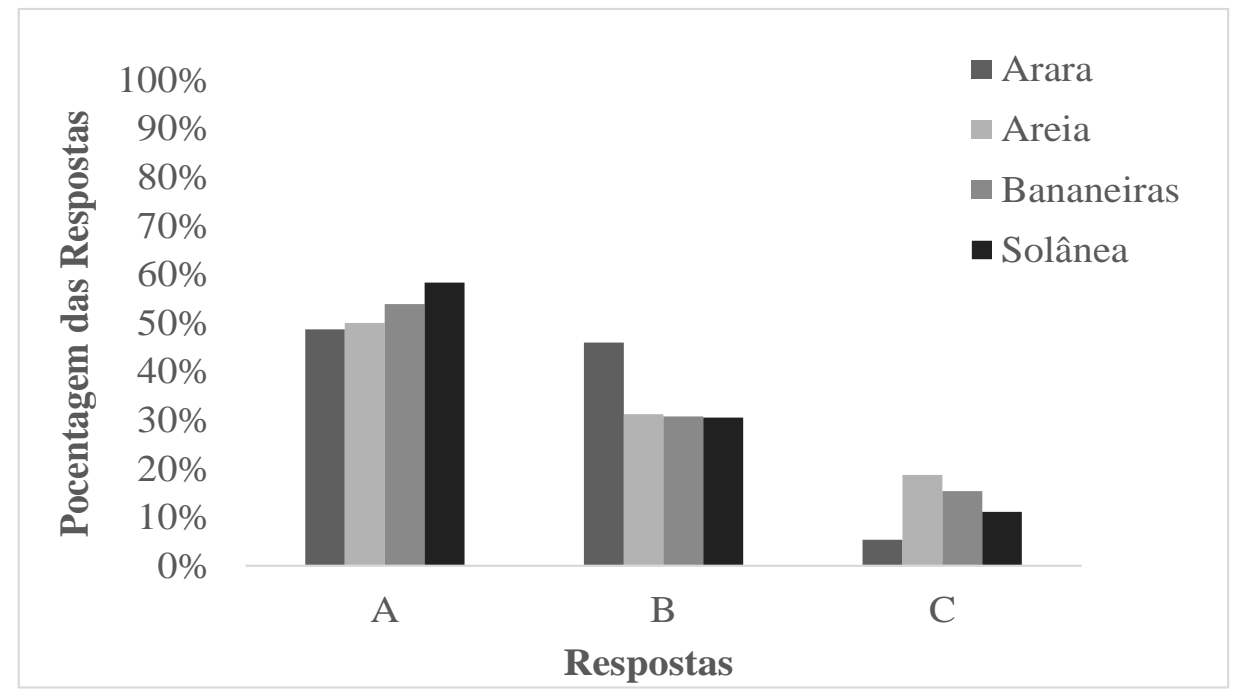

Fonte: Autores.

Desta forma, observa-se que a maioria dos estudantes das cidades de Bananeiras e Solânea, afirmaram que apresentam dificuldades de aprendizagem no ensino de Química, representados com percentuais acima de 50\%. Percebe-se que os estudantes de Arara e Areia também apresentam dificuldades de aprender os conteúdos, o que está representado na Figura 5 com percentuais abaixo de $50 \%$.

Assim, é notável a opinião dos estudantes acerca das dificuldades que possuem para aprender Química, pois podem considerá-la complexa, devido à utilização excessiva de práticas de ensino baseadas no uso de fórmulas Químicas, cálculos matemáticos, memorização de regras, entre outros, que pouco colabora para compreender e resolver uma situação-problema presente no contexto sociocultural do estudante. Para Santos, Borges, Borges, Marciano, Brito, Carneiro, Epoglou, \& Nunes (2012), a dificuldade ou não de gostar dos conteúdos de disciplinas como Química, Física e Matemática, está associado ao fato do uso de metodologias inadequadas, as quais supervalorizam a memorização de fórmulas, regras e cálculos, desconsiderando o desenvolvimento de habilidades e competências que o aluno precisa exercer como cidadão. Nesse aspecto, é responsabilidade do professor fazer com que os alunos mudem suas concepções, e aprendam os conteúdos numa perspectiva contextualizada, priorizando situações-problemas presentes no seu dia a dia, tornando a dinâmica das aulas mais motivadoras.

Observa-se que os dados das Figuras 3 e 5 estão interligados, uma vez que, compreender a importância do estudo da Química está diretamente associado ao nível de dificuldade enfrentado pelos discentes em sala de aula, o que pode ter relação com a própria metodologia adotada pelos docentes no processo do ensino.

Nesta perspectiva, Kempa (1991) afirma que as dificuldades de aprendizagem no ensino de Química, podem estar ligadas a própria natureza do conhecimento prévio ou a dificuldade de atribuir significado aos conceitos que os estudantes deverão aprender, como também se percebe dificuldades em relação as ligações entre a demanda ou complexidade de uma atividade a ser aprendida e a capacidade do estudante para organizar e processar tais informações, além da aptidão linguística e a falta de afinidade entre o estilo de aprendizagem do estudante e a didática utilizada pelo professor.

A Figura 6, apresenta a média e o desvio padrão referente a questão 3. 
Figura 6. Média e desvio padrão sobre a pergunta: Você tem dificuldade na aprendizagem do ensino de Química? A) Sim; B) Não; C) Não sei.

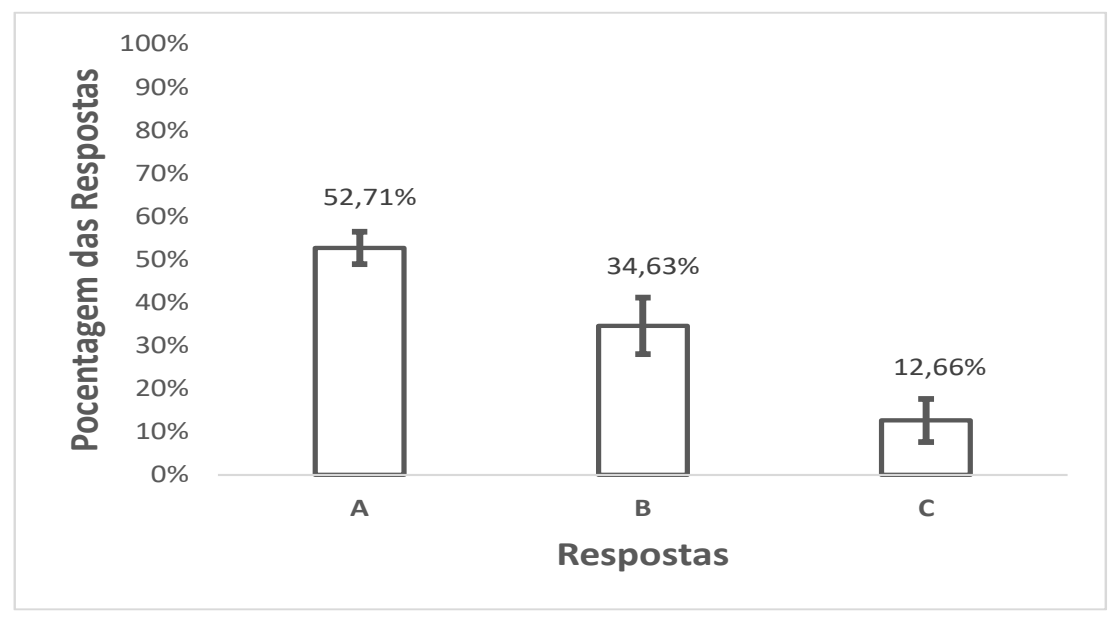

Fonte: Autores.

Na Figura 6, observa-se que a maior média e o maior desvio padrão foram de 52,71\% indicando o maior déficit de aprendizagem de Química com os estudantes das cidades de Solânea e Bananeiras, diferentemente das demais cidades. Isso pode estar relacionado com a forma em que a disciplina é ministrada, podendo refletir diretamente no aprendizado dos estudantes.

Em uma pesquisa científica desenvolvida por Klein e Ludke (2019), com estudantes do ensino médio de uma escola, observou-se algumas dificuldades por parte dos estudantes com o ensino de Química, onde foi ressaltado a importância de buscar novas metodologias para melhorar a abordagem dos conteúdos em sala de aula, através do uso de materiais didáticos diversos, tais como a experimentação, jogos e atividades lúdicas, utilização de novas tecnologias digitais da informação e comunicação, entre outros, proporcionando ao aluno um ambiente de aprendizagem mais atrativo e buscando promover motivação nos sujeitos.

Em seguida, buscou-se diagnosticar quais as dificuldades que os estudantes apresentam (Figura 7).

Figura 7. Quais os motivos das suas dificuldades em aprender Química? A) Vejo importância, mas não me dedico; B) A metodologia utilizada pelo professor não envolve o cotidiano; C) Não consigo perceber aplicação prática da Química, por isso dificulta meu aprendizado; D) É difícil de aprender por causa das regras de nomenclatura; E) Não vejo importância por isso sinto dificuldade; F) A metodologia utilizada pelo professor envolve o cotidiano, mas não me atrai; G) É difícil de aprender por causa dos cálculos; H) É difícil de aprender por causa da competição entre eu e meus colegas.

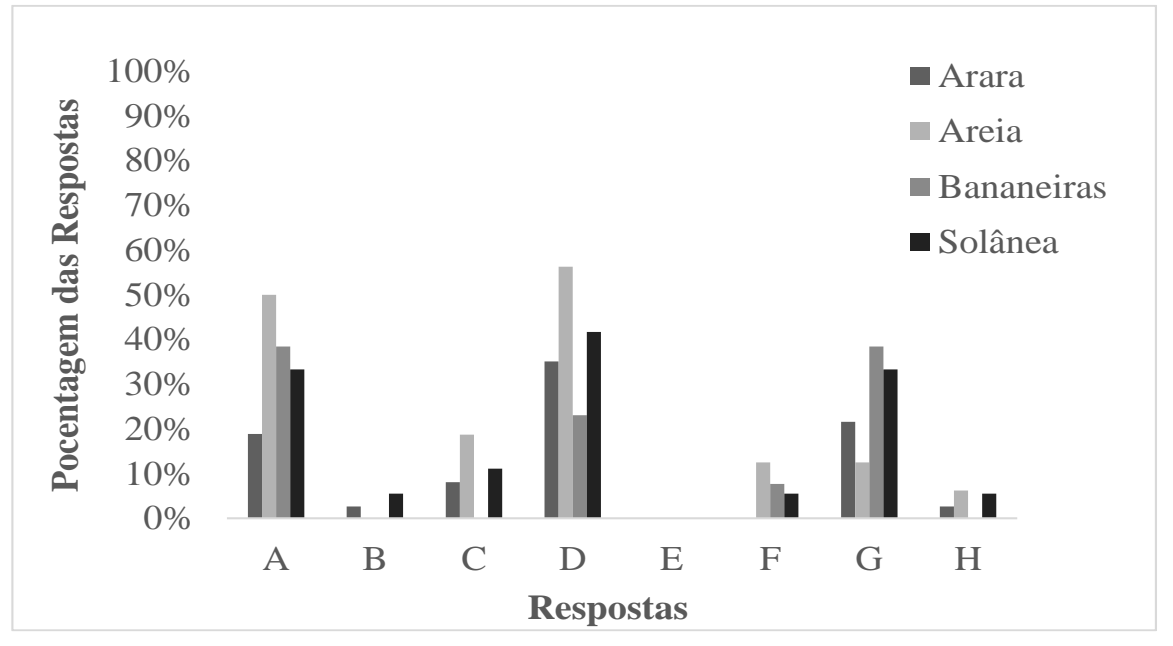

Fonte: Autores. 
Na Figura 7, estão apresentadas as dificuldades de aprendizagem reveladas pelos alunos das quatro cidades que foram fontes desta pesquisa, onde as alternativas mais escolhidas dentre os 102 alunos questionados, foram as letras A, D, G que se referem a: "vejo importância, mas não me dedico"; "É difícil de aprender por causa das regras de nomenclatura"; É difícil de aprender por causa dos cálculos".

Pesquisas revelam que no ensino de Química, percebe-se que os alunos muitas vezes não conseguem associar o conteúdo estudado com situações do seu cotidiano, o que gera desinteresse pela disciplina, em decorrência do ensino descontextualizado e não interdisciplinar adotado nas escolas (Leite \& Lima, 2015).

Na Figura 8, será apresentado a média e o desvio padrão referente a pergunta que trata sobre os motivos que geram as dificuldades de aprendizagem no ensino de Química, na concepção dos estudantes.

Figura 8. Média e desvio padrão sobre a pergunta: Quais os motivos das suas dificuldades em aprender Química?

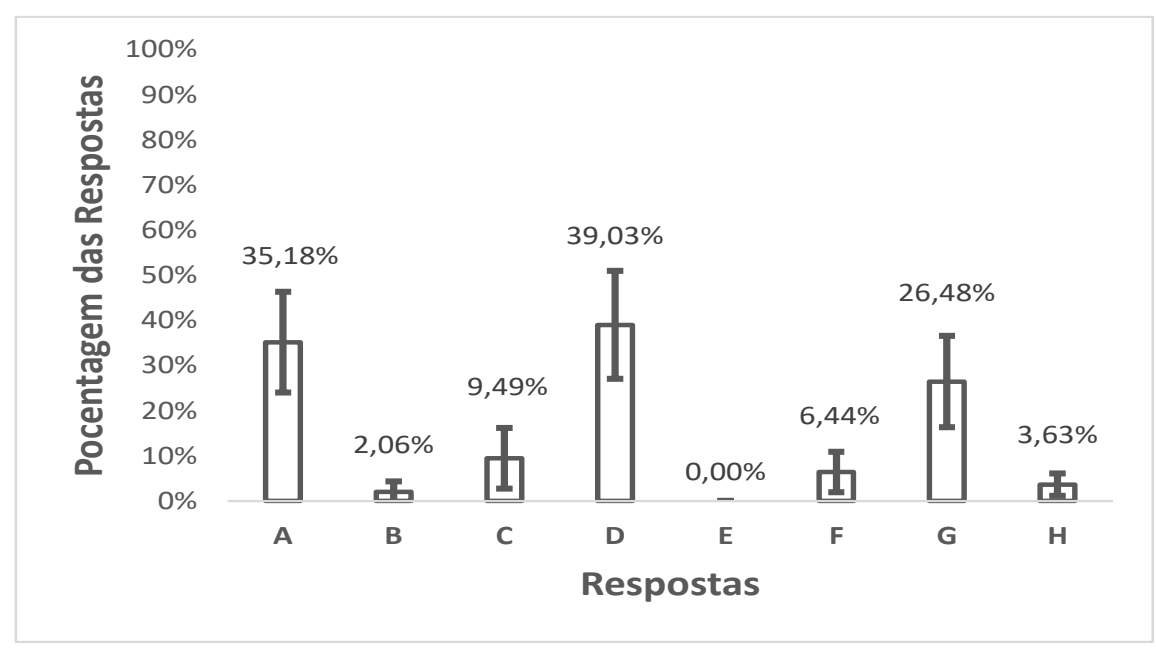

Fonte: Autores.

Esses dados revelam que as dificuldades podem estar relacionadas à falta de dedicação e esforço do estudante, ou pode ter relação com a didática empregada pelo professor, que dificulta o processo de transposição didática do conteúdo, dificultando ainda mais o aprendizado no ensino de Química.

Dando continuidade as análises, buscou-se fazer um levantamento com os estudantes, para identificar se eles gostam da disciplina de Química. Os resultados podem ser observados na Figura 9.

Figura 9. Você gosta de Química? A) Muito; B) Normal; C) Mais ou menos; D) Pouco; E) Não gosto.

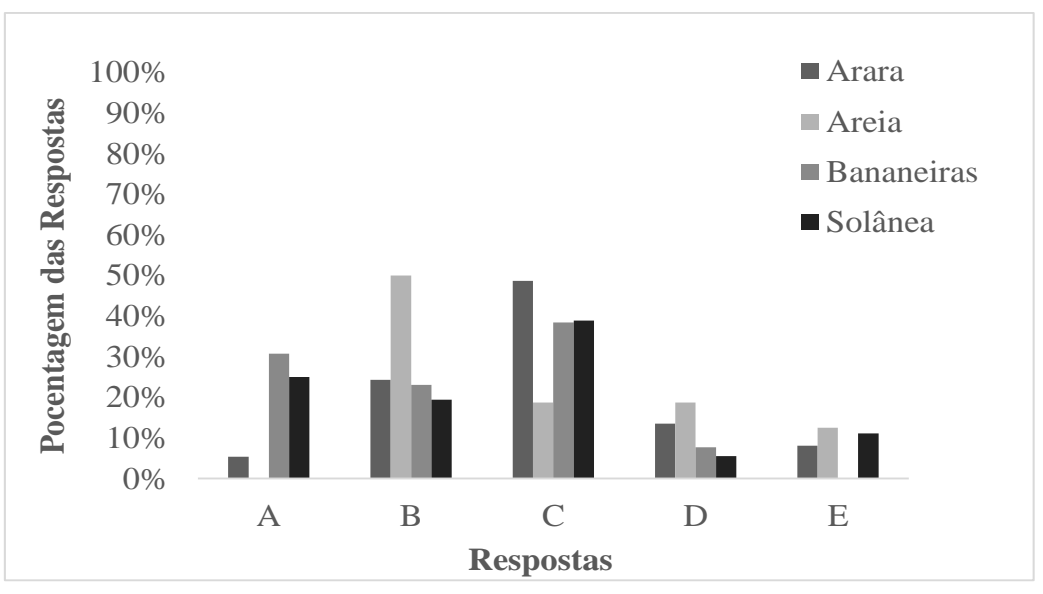

Fonte: Autores. 
Nos municípios de Arara, Bananeiras e Solânea, muitos alunos responderam que gostam de estudar Química "Mais ou menos". Em Areia, a maioria respondeu que "Normal”. Logo, compreende-se que este grau de afinidade pode estar associado a pouca motivação que os estudantes possuem pela disciplina. Ademais, em alguns casos, esta desmotivação pode estar associada ao ensino tradicional (modelo transmissão-recepção) praticado nas escolas brasileiras. Sobre esta questão, é possível afirmar,

O ensino de Química brasileiro ainda segue, em muitos casos, padrões tradicionalistas que por muito tempo nortearam a aprendizagem das ciências. Na maioria das vezes, as aulas são expositivas, distanciadas dos contextos científicos, tecnológicos e sociais, levando os estudantes a apresentarem resistência à aprendizagem da disciplina (Oliveira, Silva, \& Melo, 2020, p. 110).

Para Alarcão (2010), fazer com que os alunos apresentem estímulos e vontade em aprender uma disciplina, consiste em estabelecer uma afinidade entre o estudante e o conteúdo estudado, tendo como princípio norteador de sua prática pedagógica a preocupação em dar liberdade e responsabilidade ao seu aluno, pois através destas ações pedagógicas, ele passará a ter autonomia, superando as dificuldades enfrentadas no processo de ensino-aprendizagem.

Constatou-se, de acordo com os dados da Figura 9, que apesar das dificuldades de aprendizagem já reveladas neste trabalho de pesquisa, alguns dos estudantes das cidades de Arara, Bananeira e Solânea, gostam de Química. É importante destacar que, a motivação é de extrema relevância no processo de ensino e aprendizagem, pois consegue despertar interesse dos estudantes em determinado conteúdo.

Estudo realizado por Leite e Lima (2015), em uma escola de Ensino Médio do Nordeste Brasileiro, com 91 alunos do $2^{\circ}$ e $3^{\circ}$ anos, revela que dos estudantes que assinalaram gostar de estudar Química, 38 alunos (41,7\%) atribuíram isso ao fato do professor explicar bem os conteúdos, 31 (34,1\%) ao fato de considerarem a importância da Química em suas vidas e 22 $(24,2 \%)$ ao fato de as aulas serem boas. Esses dados reforçam a importância do professor adotar boas práticas de ensino, buscando minimizar a falta de motivação pelo estudo desta ciência, o que consequentemente estará colaborando para diminuir as suas dificuldades de aprendizagem.

A Figura 10, apresenta a média e o desvio padrão referente a questão 5.

Figura 10. Média e desvio padrão sobre a pergunta: Você gosta de Química? A) Muito; B) Normal; C) Mais ou menos; D) Pouco; E) Não gosto.

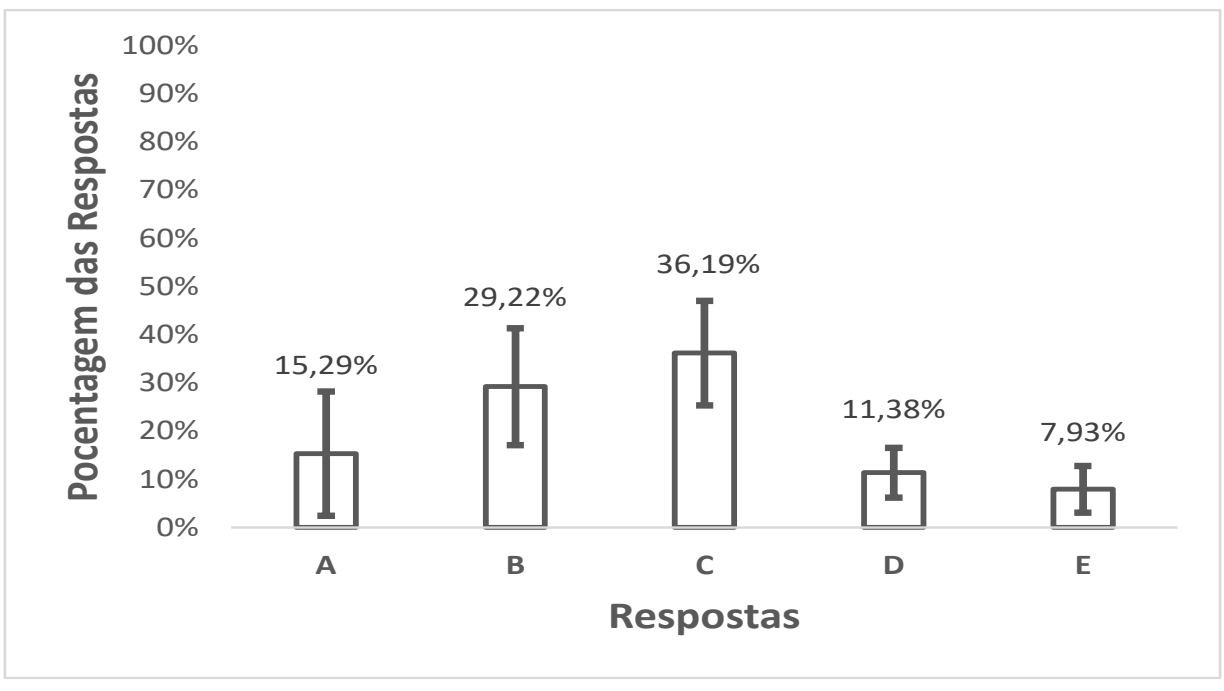

Fonte: Autores. 
Ao indagar os estudantes: Você gosta de Química? Percebe-se a partir dos dados que, 36,19\% dos estudantes gostam mais ou menos de Química e 29,22\% afirmaram gostar normalmente desta disciplina (Figura 10). Dessa forma, fica perceptível como é importante o professor incentivar cada vez mais os estudantes para aprender Química. Torna-se necessário que o professor se aproprie das diferentes abordagens de ensino, buscando colaborar de forma construtiva com a aprendizagem dos alunos.

Segundo Bzuneck (2009), os problemas referentes à falta de motivação refletem diretamente na aprendizagem dos alunos, pois os sujeitos ficam desanimados, gerando desmotivação pelos estudos, e consequentemente aprendem muito pouco por não conseguirem desenvolver habilidades e competências necessárias para aprender esta ciência dentro de uma perspectiva construtiva.

Em seguida, buscou-se levantar entre os estudantes, se eles se sentem motivados para estudar Química. As respostas podem ser observadas na Figura 11.

Figura 11. Você se sente motivado a estudar Química? (A) Sim; (B) Não; (C) Às vezes.

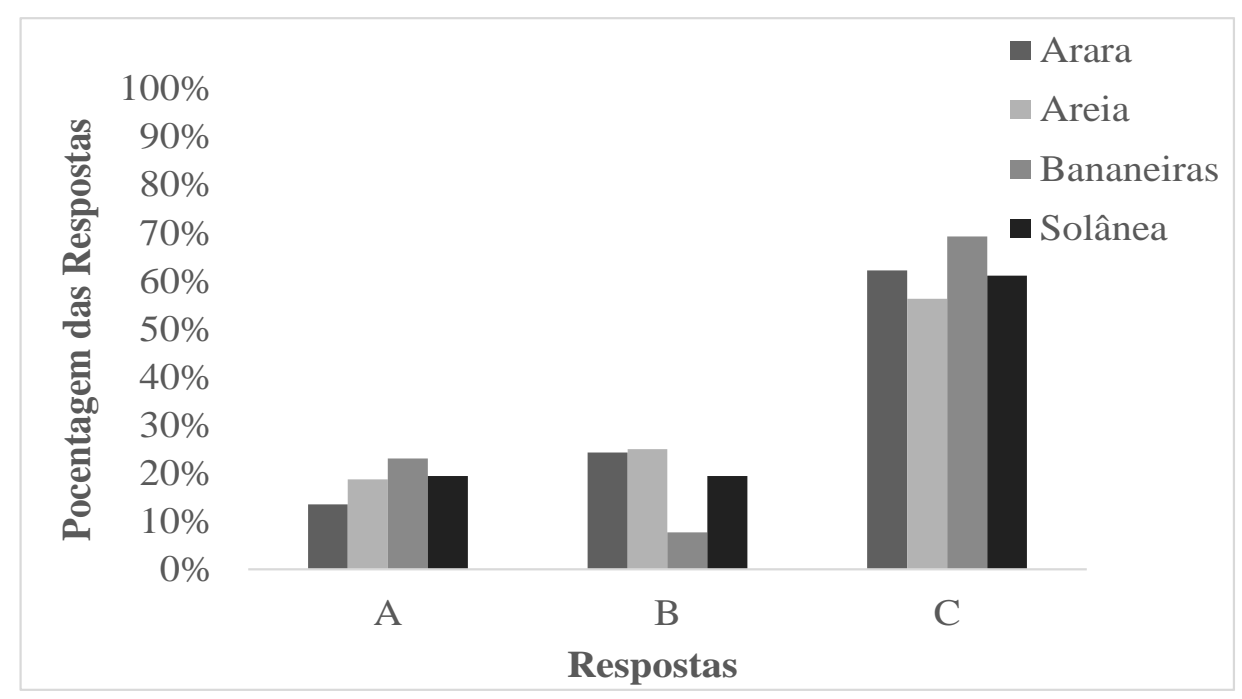

Fonte: Autores.

Na Figura 11, percebe-se que a maioria dos alunos das 4 cidades, relatam que "às vezes" se sentem motivados em aprender Química. Esses resultados revelam que ainda há certa resistência dos estudantes para aprender esta ciência, sendo necessário que o professor possa colaborar com o desenvolvimento de ações pedagógicas que possam ajudá-los a despertar o interesse em estudar Química. Pessoa e Alves, revelam que,

[...] outros construtos importantes no desenvolvimento dos estudantes deixam de ser considerados como o de levá-los a gostar de explorar seus contextos de vivências e o de desenvolver a criatividade, a autonomia e a autoconfiança na solução de situações-problema com as quais se deparam no dia a dia (Pessoa \& Alves, 2011, p. 2).

Compreende-se a necessidade de que os docentes possam pensar em utilizar diferentes abordagens de ensino, tais como jogos didáticos e atividades lúdicas, filmes, experimentos com materiais alternativos de baixo custo, dentro de uma perspectiva investigativa ou problematizadora, utilização das tecnologias digitais da informação e comunicação, história da ciência, entre outros, buscando melhorara compreensão e despertar motivação dos alunos nas aulas de Química. 
Além disso, compreende-se que o processo de ensino e aprendizagem de conceitos científicos deve ser adaptado conforme a capacidade intelectual dos alunos, de modo que, tornem os conhecimentos mais interessantes, elevando a eficiência do processo educacional (Andrade, 2015; Silva, Sales, \& Silva, 2019).

Um estudo de caso realizado com discentes do $1^{\circ}$ ano do ensino médio no município de Cajazeiras - PB, mostrou que a utilização de metodologias alternativas abordadas na sala de aula, além de motivar os discentes durante as aulas que geralmente são realizadas apenas com atividades monótonas, colabora para se desenvolver uma aprendizagem prazerosa no processo de ensino-aprendizagem, sendo necessário inseri-las para facilitar o entendimento dos conteúdos científicos (Silva, Sales, \& Silva, 2017).

Para que o aprendizado dos alunos ocorra de maneira eficaz, é necessário que de alguma forma ele seja inserido no processo como sujeito ativo. Mas para que isso ocorra efetivamente, o aluno tem que estar motivado, totalmente inserido no processo de ensino-aprendizagem despertando assim, o interesse em aprender determinado conteúdo da ciência (Delizoicov, Angotti e Pernambuco, 2011).

A Figura 12, apresenta a média e o desvio padrão referente a questão 6.

Figura 12. Média e desvio padrão sobre a pergunta: Você se sente motivado a estudar Química? Sim; B) Não; C) Às vezes.

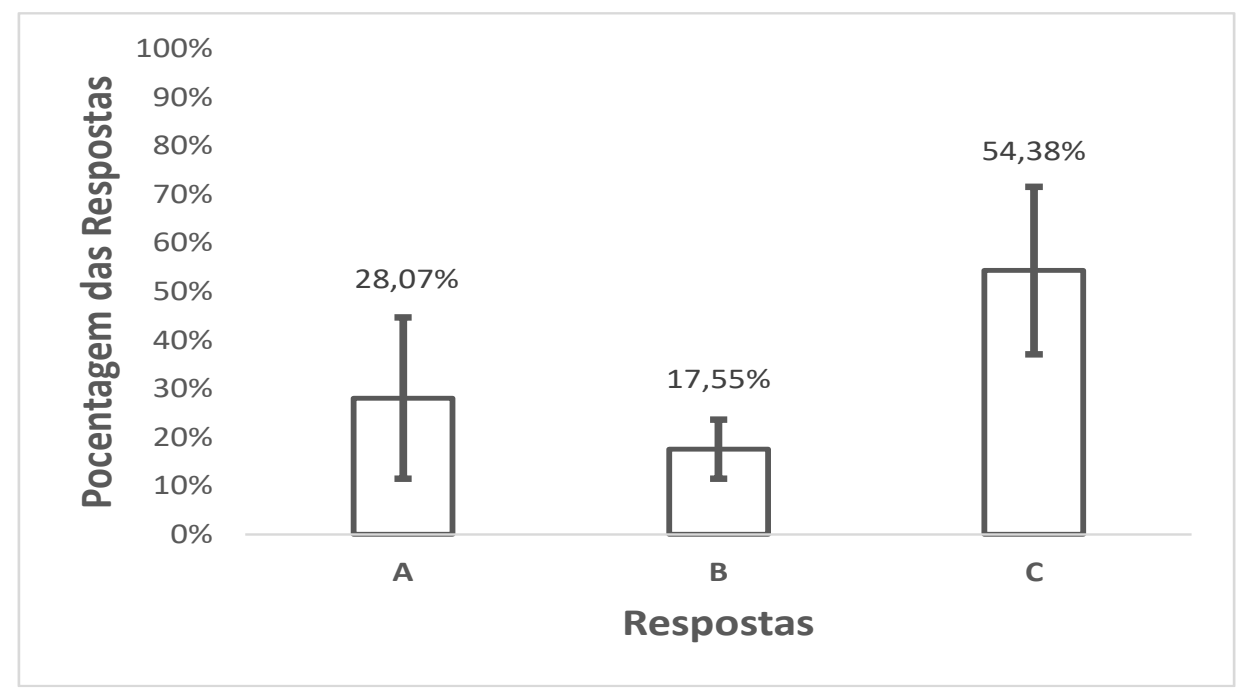

Fonte: Autores.

54,38\% das respostas referem-se a falta de motivação dos estudantes para aprender Química (Figura 12). Assim, para melhorar essa motivação e o rendimento dos alunos em sala de aula, é fundamental planejar atividades diversificadas, pois a mudança de práticas, podem colaborar para potencializar a aprendizagem, despertando motivação em aprender, tornando o aprendizado mais eficaz e interessante, já que algumas tarefas rotineiras em sala de aula, não colaboram para melhorar o rendimento de muitos alunos.

\section{Considerações Finais}

A partir deste estudo, constatamos a importância de se investigar as percepções dose estudantes acerca do processo de ensinar e aprender a disciplina de Química. Com isso, foi possível compreender e refletir quais as ações do professor podem ser repensadas, aprimoradas e quais as dificuldades, que às vezes são recorrentes, podem ser sanadas. Além disso, novas estratégias e ferramentas também podem ser incorporadas na prática docente, conforme averiguamos neste estudo. Torna-se necessário a utilização de diferentes abordagens de ensino alinhadas a diferentes recursos, para que eles encontrem significados para aprendizagem de conceitos químicos. 
Assim sendo, é imprescindível que ocorra mudanças no processo de ensino-aprendizagem na disciplina de Química, devendo essas, estar voltadas para a problematização desta Ciência, com foco no desenvolvimento da alfabetização científica, visando à formação do estudante para o exercício crítico da cidadania.

Compreende-se a partir do olhar lançado neste estudo, que há uma necessidade de cada vez mais lutar em sala de aula, para minimizar as dificuldades que os estudantes enfrentam no ensino de Química, buscando despertar interesse e motivação para aprender os conteúdos desta ciência.

Algo que também destacamos, que emergiu ao longo deste estudo, diz respeito ao uso da contextualização e da interdisciplinaridade no ensino e aprendizagem de Química, como uma abordagem que pode ser alinhada ao uso de diferentes metodologias participativas, como um caminho para melhorar o entendimento e promover reflexão nos estudantes acerca de muitos conceitos químicos que podem ser articulados com o contexto sociocultural de cada estudante. Nesse sentido, os estudantes perceberão a importância da disciplina na sua vida e nas relações do homem com a natureza.

Por fim, salientamos que o educador tem a função de melhorar a sua abordagem de ensino adotada para que os educandos sejam motivados a aprender e percebam que existe uma aplicação dos conteúdos químicos em sua vida profissional e pessoal, pois a ciência está presente na vida de cada cidadão.

Sugerimos como proposta para trabalhos futuros a realização de entrevistas com os participantes através de um roteiro previamente elaborado.

\section{Referências}

Alarcão, I. (2010). Professores reflexivos em uma escola reflexiva. (2010). https://pt.slideshare.net/valdecicorreia/isabel-alarco-professores-reflexivos-emuma-escola-reflexiva-2929515.

Andrade, J. S. (2015). A abordagem de modelos atômicos para alunos do $9^{\circ}$ ano do ensino fundamental pelo uso de modelos e modelagem numa perspectiva histórica. 158 f. Dissertação (Mestrado Profissional em Ensino de Ciências) - Universidade de Brasília, Distrito Federal, Brasil. http://dx.doi.org/10.26512/2015.04.D.19007

Bastos, F., Nardi, R., Diniz, R. E. S., \& Caldeira, A. M. A. (2004). Da necessidade de uma pluralidade de interpretações acercado do processo de ensino e aprendizagem em Ciências: revisitando os debates sobre o construtivismo. In: R. Nardi, F. Bastos, R. E. da S. Diniz. (Org.). Pesquisa em ensino de Ciências: contribuições para a formação de professores. 9-56, Escrituras Editora.

Bzuneck, J. A. (2009). A motivação do aluno: Aspectos introdutórios. In: E. Boruchovitch \& J. A. Bzuneck. (Orgs.). A Motivação do Aluno. Contribuições da Psicologia Contemporânea. (4a. ed.), 9-36. Editora Vozes.

Delizoicov, D., Angotti, J. A. P., \& Pernambuco, M. M. C. A. (2011). Ensino de Ciências: Fundamentos e Métodos. (4a ed). Cortez. http://dx.doi.org/10.1590/1516-73132014000300007.

Diehl, A. A. (2004). Pesquisa em ciências sociais aplicadas: métodos e técnicas. Prentice Hall.

Fachin, O. (2003). Fundamentos de metodologia. (4a. ed.), Saraiva.

Freire, M. S., Silva Júnior, C. N. S., \& Silva, M. G. (2011). Dificuldades de aprendizagem no ensino de eletroquímica segundo licenciandos de Química. In Encontro Nacional de Pesquisa em Ensino de Ciências, 5. http://www.nutes.ufrj.br/abrapec/viiienpec/resumos/R1150-1.pdf

Giacomini, A., \& Muenchen, C. (2015). Os três momentos pedagógicos como organizadores de um processo formativo: algumas reflexões. Revista Brasileira de Pesquisa em Educação em Ciências, 5(2), 339 - 355. https://periodicos.ufmg.br/index.php/rbpec/article/view/4317/2882.

Kempa, R. F. (1991). Students' learning difficulties in science. Causes and possible remedies. Enseñanza de las Ciencias, 9(2), 119-128. https://ddd.uab.cat/pub/edlc/02124521v9n2/02124521v9n2p119.pdf.

Kubo, O. M., \& Botomé, S. P. (2001). Ensino-aprendizagem: uma interação entre dois processos comportamentais. Interação em Psicologia, 5, 1-19. https://revistas.ufpr.br/psicologia/article/view/3321.

Klein, V., \& Ludke, E. (2019). Uma investigação sobre motivação de estudantes frente a aulas de Química orgânica no ensino médio. Revista vivências. 15 (29), 81-99. https://doi.org/10.31512/vivencias.v15i29.53.

Leite, L. R., \& Lima, J. O. G. D. (2015). O aprendizado da Química na concepção de professores e alunos do ensino médio: um estudo de caso. Revista Brasileira de Estudos Pedagógicos, 96(243), 380-398. https://www.scielo.br/scielo.php?pid=S2176-66812015000200380\&script=sci_arttext.

Lima, J. O. G., \& Leite, L. R. (2012). O processo de ensino e aprendizagem da disciplina de Química: o caso das escolas do ensino médio de Crateús/Ceará/Brasil. Revista electrónica de investigación em educación em ciencias, 7(2), 72 - 85. http://ppct.caicyt.gov.ar/index.php/reiec/article/view/7485. 
Mendonça, A. M. G. D., \& Pereira, D. L. (2014). Ensino de Química: realidade docente e a importância da experimentação para o processo de aprendizagem. In: Encontro de Iniciação à docência da UEPB, 5. Campina Grande, Brasil. https://editorarealize.com.br/artigo/visualizar/11662.

Mól, G. S. (2017). Pesquisa qualitativa em ensino de Química. Qualitative Research Journal, 5(9), 495-513. https://editora.sepq.org.br/rpq/article/view/140.

Oliveira, R. C. B., Silva, I. S., \& Melo, C. C. (2020). Implicações do uso de situação-problema no ensino básico para compreensão de fenômenos associados à chuva ácida. Revista Ciências \& ideias, 11(1), 108-122. https://revistascientificas.ifrj.edu.br/revista/index.php/reci/article/view/1149.

Ouriques, E. B., Ferreira, L, O., Welter, L., Braibante, M. E. F., \& Reis, M. T. (2019). Curiosidades que a Química explica: um jogo com abordagem diferenciada para o ensino de Química. Revista Debates em Ensino de Química, 4(2), 252-265. http://journals.ufrpe.br/index.php/REDEQUIM/article/view/2006.

Pereira, A. S., Shitsuka, D. M., Parreira, F. J., \& Shitsuka, R. (2018). Metodologia da pesquisa científica. UFSM. https://repositorio.ufsm.br/bitstream/handle/1/15824/Lic_Computacao_Metodologia-Pesquisa-Cientifica.pdf?sequence=1 .

Richardson, R. J. (1999). Pesquisa social: métodos e técnicas. Atlas.

Santos, D. G., Borges, A. P. A., Borges, C. O., Marciano, E. P., Brito, L. C. C., Carneiro, G. M. B., Epoglou, A., \& Nunes, S. M. T. (2012). A Química do lixo: utilizando a contextualização no ensino de conceitos químicos. Revista Brasileira de Pós-Graduação, 8 (2), 421-443. http://ojs.rbpg.capes.gov.br/index.php/rbpg/article/view/241.

Severino, A. J (2007). Metodologia de trabalho científico. (23a ed.). Cortez. https://edisciplinas.usp.br/pluginfile.php/4243 422/mod_resource/content/1/SEVERINO.pdf.

Silva, I. C. T., Siqueira, V. F., \& Goi, M. E. J. (2019). Relatos de Estágio Supervisionado no Ensino de Química. Revista Debates em Ensino de Química. 5(2), 39-54. http://www.journals.ufrpe.br/index.php/REDEQUIM/article/view/2417.

Silva, F., Sales, L. L. M., \& Silva, M. D. N. (2019). O uso de metodologias alternativas no ensino de Química: um estudo de caso com discentes do $1^{\circ}$ ano do ensino médio no município de Cajazeiras-PB. Revista de Pesquisa Interdisciplinar, $2(2)$, 333 - 344. http://revistas.ufcg.edu.br/cfp/index.php/pesquisainterdisciplinar/article/view/372/pdf.

Pessoa, W. R., \& Alves, J. M. (2011). Motivação para estudar Química: configurações subjetivas de uma estudante do segundo ano do ensino médio. In Encontro nacional de pesquisa em educação em ciências, 8. Campinas, Brasil. http://abrapecnet.org.br/atas_enpec/viiienpec/resumos/R0164-1.pdf

Vargas Júnior, L. (2012). Síntese das concepções das teorias interacionistas de Piaget e Vygotsky. Portal Educação. https://siteantigo.portaleducacao.com.br/conteudo/artigos/pedagogia/sintese-das-concepcoes-das-teorias-interacionistas-de-piaget-e-de-vigotsky/19420. 